\title{
Unmet health care needs for persons with environmental sensitivity
}

\author{
This article was published in the following Dove Press journal: \\ Journal of Multidisciplinary Healthcare \\ 23 January 2015 \\ Number of times this article has been viewed
}

\author{
Pamela Reed Gibson \\ Shannon Kovach \\ Alexis Lupfer \\ Department of Psychology, \\ James Madison University, \\ Harrisonburg, VA, USA
}

Correspondence: Pamela Reed Gibson Department of Psychology, James Madison University, MSC 7704, $91 \mathrm{E}$ Grace St, Harrisonburg, VA 22807, USA Email gibsonpr@jmu.edu

\begin{abstract}
Studies of unmet health care needs have shown that women, people with poor health, and people with lower socioeconomic status are more likely to report having unmet health care needs. In this study, we examined the types of and reasons for unmet health care needs in 465 people with environmental sensitivities. A second area of inquiry involved negative reactions to general anesthesia. Results showed that the most common barriers to receiving care were the inability to find a provider who understands environmental sensitivities and a lack of accessibility due to chemical and electromagnetic exposures in health care environments. Lower income and poorer health (longer illness, a worsening or fluctuating course of illness, and a higher level of disability) were significantly correlated with the total number of reported unmet health care needs. Some people with environmental sensitivities reported having negative reactions to anesthesia of long duration; most common were nausea and vomiting, fatigue, and reduced cognitive ability.
\end{abstract}

Keywords: environmental sensitivity, chemical sensitivity, electrohypersensitivity, chemical hypersensitivity, chemical intolerance, contested illness

\section{Introduction}

Unmet health care needs are reported by persons with a variety of health conditions and particularly by women. ${ }^{1}$ Washington et $\mathrm{al}^{2}$ found that factors highly correlated with unmet health care needs among women veterans included being of a younger age, not having insurance, being part of an ethnic or racial minority, being in poor health, or having been diagnosed with a mental health disorder. Women veterans attributed their unmet needs most commonly to the inability to afford proper health care and, secondly, to the inability to take time off of work for the appointment. ${ }^{2}$ Wiltshire et $\mathrm{al}^{3}$ examined the impact of socioeconomic status (SES) and other factors on the differences between the unmet health care needs of African American and Caucasian women. Although no significant race-based differences in unmet needs were found, the level of participants' educational attainment was positively correlated with the number of unmet medical needs reported. In addition, participants with low SES, inadequate insurance coverage, and poorer health were more likely to report unmet medical needs. ${ }^{3}$ Bryant et $\mathrm{al}^{4}$ found that the sociodemographic factors most predictive of unmet health care needs included having been divorced or widowed, making less than US\$40,000 annually, and being unemployed.

Some researchers have found that younger people are more likely to be uninsured or lack a regular care provider. ${ }^{2}$ Being in poor health also correlated with high levels of reported unmet health care needs. ${ }^{5}$ For example, Ugalde et al ${ }^{6}$ found that patients 
with lung cancer indicated high levels of unmet medical, communication, psychological, and emotional needs. Hwang et $\mathrm{al}^{7}$ studied male veterans with advanced cancer, and $88.7 \%$ reported unmet physical health care needs. The 18-30-year age group was found to report the highest rates of unmet health care needs. Those with unmet mental health care needs report acceptability (measured by attitudes toward illness, health care providers, or the health care system) as the most common cause of unmet needs. ${ }^{8}$ Female gender is also highly associated with unmet mental health care needs, and people with a mental illness may refuse to seek health care services due to fear of stigmatization by others. ${ }^{8}$

Barriers to access, long wait times, and lacking a sense of community or social support are additional reasons commonly cited for having unmet medical needs. ${ }^{4}$ In persons with physical, sensory, and cognitive disabilities, McColl et $\mathrm{al}^{9}$ found three times as many unmet health care needs as among the nondisabled (17.5\% versus $5.2 \%)$, with long waits, inadequate care, unavailability, and cost the most often cited reasons for not receiving care. Those who report unmet needs often ultimately use more health care services than their medical condition typically would have required if they had been treated in a timely manner. ${ }^{1}$

Chemical sensitivity (CS), also referred to as multiple $\mathrm{CS}$, chemical intolerance, and chemical hypersensitivity, is a chronic disability marked by negative health reactions to common chemicals in ambient air. Common triggers include perfumes, paints, exhausts, cleaners, pesticides, and others. Physical reactions range from mild to life threatening and may affect any organ system including the respiratory, digestive, neurological, cardiovascular, immune, or other systems. ${ }^{10,11}$ People with CS, therefore, have to avoid exposure to a large number of chemicals, which greatly affects their access to daily living and working environments.

CS affects $12.6 \%$ of the United States population ${ }^{12}$ and is reported and studied in a number of other countries as well, including Sweden, ${ }^{13,14}$ the Netherlands, ${ }^{15}$ Germany, ${ }^{16}$ and Japan. ${ }^{17,18}$ Higher numbers of women than men report CS.

Life impact research regarding CS has shown that CS is associated with high unemployment, ${ }^{19,20}$ low social support, ${ }^{21}$ a lack of access to community resources, ${ }^{22}$ and a history of repeated attempts to obtain helpful treatment. ${ }^{23}$ Only one preliminary study has addressed unmet health care needs in those with CS. Engel et $\mathrm{al}^{24}$ found that for 187 persons, the most common obstacles to obtaining medical treatment were chemical barriers in medical offices (including perfume on providers) and the lack of practitioners' knowledge regarding $\mathrm{CS}$.
Also related to, and overlapping with, CS is the problem of electrohypersensitivity (EHS). Though EHS has not been widely researched and has suffered from disbelief from some sectors, persons with EHS manifest cellular changes similar to those induced by ionizing radiation or ultraviolet light. ${ }^{14}$ Hence, Johansson ${ }^{25}$ believes that the cutaneous changes found in persons with EHS (eg, mast cell degranulation and other changes) are a form of radiation damage. The presence of mast cells in cardiac tissue may explain the heart symptoms experienced by some persons reporting EHS when they use video display terminals. ${ }^{25}$ The Bioinitiative Report, ${ }^{26}$ authored by 14 scientists and public health experts, summarized the research on EHS and identified cell phone use and cordless phone use as risk factors for brain tumors and acoustic neuromas. Extremely low electromagnetic frequency has been identified as a risk factor for breast cancer, childhood leukemia, and even Alzheimer's disease. Rizi and Dehghan ${ }^{27}$ found a spate of self-reported physical symptoms as well as elevated psychological problems among workers at highvoltage facilities.

Together, CS and EHS make up what we refer to as environmental sensitivities (ES). The purpose of the present study was to examine the presence of and reasons for unmet health care needs among people with ES. Additionally, given that the inability to tolerate anesthesia has been cited as a reason for avoiding medical interventions among those with $\mathrm{CS}$ in particular, ${ }^{24}$ we were interested in assessing whether any of the respondents who had undergone a major medical surgery under anesthesia in the past year had had negative side effects as a result.

Given that SES/affordability and accessibility are often cited as the largest barriers to receiving proper medical care, we believed that many participants in our study would also list these as barriers. We also predicted that people would cite chemical barriers in the medical environment and the lack of providers who understand CS as reasons for unmet needs. We also hypothesized that some of those who had received anesthesia would report negative reactions due to use.

\section{Materials and methods Participants}

Participants were 465 persons with self-reported ES; 86\% were female and 14\% were male. Transgender, intersex, queer, and questioning individuals were also represented in small numbers. Participants reported the following sexual orientations: straight (88\%); gay (4\%); bisexual (4\%); and pansexual $(1 \%)$. The mean age was 52.7 years. Participants reported being of the following racial backgrounds: 
Caucasian (94.1\%); mixed race (2.63\%); African American (0.66\%); Latina/Latino (0.88\%); Asian (0.66\%); and Arabic/ Middle Eastern (0.66\%). Participants resided mainly in the US (number $[n]=332$ ), but respondents from Australia $(n=43)$, Canada $(n=37)$, the United Kingdom $(n=24)$, New Zealand $(n=4)$, Dominica $(n=1)$, Spain $(n=1)$, and Malaysia $(n=1)$ also participated in the study (Table 1). The majority of participants held graduate (31\%) or undergraduate degrees (28\%); others had 2-year degrees (7\%), some college (20\%), technical or trade school training $(5 \%)$, high school $(9 \%)$, or less than high school (1\%).

Table I Demographics

\begin{tabular}{|c|c|c|}
\hline & Number & $\%$ \\
\hline \multicolumn{3}{|l|}{ Gender* } \\
\hline Female & 394 & 85.84 \\
\hline Male & 64 & 13.94 \\
\hline Queer & 4 & 0.87 \\
\hline Transgender & 3 & 0.65 \\
\hline Questioning & 2 & 0.44 \\
\hline Intersex & 2 & 0.44 \\
\hline \multicolumn{3}{|l|}{ Age } \\
\hline $18-25$ years & 8 & 1.77 \\
\hline $26-33$ years & 13 & 2.89 \\
\hline $34-41$ years & 53 & 11.70 \\
\hline $42-49$ years & 82 & 18.10 \\
\hline $50-57$ years & 139 & 30.68 \\
\hline $58-65$ years & 106 & 23.40 \\
\hline $66-73$ years & 35 & 7.73 \\
\hline $74-81$ years & 14 & 3.10 \\
\hline $82-89$ years & 2 & 0.56 \\
\hline 90 years or over & I & 0.44 \\
\hline Did not answer & 12 & 2.65 \\
\hline \multicolumn{3}{|l|}{ Race } \\
\hline Caucasian & 432 & 94.1 \\
\hline Mixed race & 12 & 2.63 \\
\hline Latino/Latina & 4 & 0.88 \\
\hline African American & 3 & 0.66 \\
\hline Asian & 3 & 0.66 \\
\hline Arabic/Middle Eastern & 3 & 0.66 \\
\hline \multicolumn{3}{|l|}{ Sexual preference } \\
\hline Straight & 402 & 88.16 \\
\hline Gay & 18 & 3.95 \\
\hline Bisexual & 18 & 3.95 \\
\hline Asexual & 13 & 2.85 \\
\hline Pansexual & 5 & 1.10 \\
\hline \multicolumn{3}{|l|}{ Country of residence } \\
\hline United States & 332 & 71.40 \\
\hline Australia & 43 & 9.25 \\
\hline Canada & 37 & 7.96 \\
\hline United Kingdom & 24 & 5.16 \\
\hline New Zealand & 4 & 0.22 \\
\hline Dominica & 4 & 0.22 \\
\hline Spain & 1 & 0.22 \\
\hline Malaysia & I & 0.22 \\
\hline
\end{tabular}

Notes: *More than one response per participant possible. Percentages do not add to 100 .

\section{Materials}

The survey consisted of 47 questions regarding demographic information and health care experiences of individuals with ES. We asked about insurance coverage, having a regular provider, having accessed 12 particular types of care in the previous year, and having unmet needs in 12 medical areas (primary, dental, eye, dermatology, female care (eg, gynecololgical care), male care (eg, prostate exams), allergy/ immunology, respiratory, neurology, gastroenterology, mental health, and other), reasons for those unmet needs, and possible negative reactions to general anesthesia following surgery. For each type of care, we supplied a checklist of the possible reasons for unmet needs constructed from the literature on unmet health care needs among persons with chronic illness and disability. We also asked participants about the level of distress associated with each type of unmet health care need on a scale of $0-10$, with 0 being no distress and 10 being extreme distress. Questions regarding participants' development of and course of their condition, as well as their current level of disability, were also included in the survey.

\section{Procedure}

After receiving approval from our institutional review board, we recruited respondents through online ES support groups and newsletters and through the research website for our laboratory, http://www.mcsresearch.net. Interested persons were asked to complete the survey through Qualtrics, an online survey tool. We also sent email alerts to a variety of online support groups for persons with chemical and electrical sensitivities, asking them to inform their members of our study. Thus, our participants were a convenience sample of volunteers with some snowball sampling. Persons who experienced electromagnetic sensitivities or who were otherwise limited from using computers were offered the option of receiving a hard copy of the survey through the mail. The responses from the returned mailed surveys were also entered into Qualtrics so these responses could be analyzed with the electronic responses. Results were analyzed using SPSS. Demographics and unmet needs were analyzed using descriptive analyses; open-ended questions were tallied and coded for categorization. A correlation matrix was constructed with major variables.

\section{Results}

Most participants were unemployed (66\%) despite the fact that many had college degrees. Some participants worked full time outside the home $(12 \%)$, part time outside the home $(6 \%)$, full time from home $(4 \%)$, or part time from home (11\%). 
Participants' marital status was mostly married (42\%) or single (30\%) (see Table 1 for details of demographics).

Over one-third of participants $(35 \%)$ reported having lived in unusual circumstances at some point in their lives, and $8 \%$ reported currently living in unusual circumstances (for example, trailers, cars, and porches). Over one-fifth $(22 \%)$ stated that they had been homeless at some point in their lives, and 4\% were currently homeless.

Most participants reported either some decline or a mixed course of illness in the previous 2 years. Only $9 \%$ reported considerable improvement; $23 \%$ reported any improvement. Participants rated their current level of disability as mild $(6 \%)$, moderate $(35 \%)$, severe $(45 \%)$, or disabled $(14 \%)$ (Table 2). Most participants reported developing ES as a result of a combination of variables (37\%), a series of lowlevel chemical exposures (19\%), one large exposure (13\%), or "other" (21\%). Other reported causes of ES cited by ten or more persons included a physical illness, mold exposure, or unknown factors (Table 3).

Most participants reported having accessed primary health care within the past year $(67.6 \%)$. Dental care $(62.61 \%)$ and eye care $(47.26 \%)$ had also been frequently accessed. Female care, allergy and immunology care, mental health care, respiratory care, and dermatology care had been sought out to a lesser degree within the past year (Table 4). Participants who reported having needed a particular form of health care, but who had not been able to receive it were given a list of barriers to health care and asked to select which barriers they faced. The most commonly reported barrier to receiving health care was an inability to find a provider who understood their sensitivities. The second most frequently reported reason for not receiving health care was the fear of possible harm from chemical exposure in the health care setting. Not being able to afford care, not having an accessible office to go to, and not feeling well enough to go to the doctor were also commonly reported barriers to accessing

Table 2 Description of disability

\begin{tabular}{lll}
\hline & Number & $\%$ \\
\hline Course of disability over the past 2 years & & \\
Considerable decline & 138 & $30.46 \%$ \\
Slight decline & 86 & $18.98 \%$ \\
Mixed course/no change & 124 & $27.37 \%$ \\
Slight improvement & 65 & $14.35 \%$ \\
$\quad$ Considerable improvement & 40 & $8.83 \%$ \\
Current level of disability & & \\
Mild & 28 & $6.25 \%$ \\
Moderate & 157 & $35.04 \%$ \\
Severe & 202 & $45.09 \%$ \\
Disabled & 61 & $13.62 \%$ \\
\hline
\end{tabular}

Table 3 Cause of environmental sensitivities

\begin{tabular}{|c|c|}
\hline & Number \\
\hline Series of low-level exposures & 86 \\
\hline One large exposure & 59 \\
\hline Unknown & 20 \\
\hline A physical illness & 14 \\
\hline Scarlet fever & 1 \\
\hline Chlamydophila pneumoniae infection & I \\
\hline Fibromyalgia & 1 \\
\hline Psychological stress & 1 \\
\hline Combination of any of the above & 167 \\
\hline \multicolumn{2}{|l|}{ Other } \\
\hline Mold exposure & 10 \\
\hline Genetics & 5 \\
\hline Native American nationality & I \\
\hline Living environment & 4 \\
\hline Living above a laundry plant & 1 \\
\hline Sick building syndrome & 1 \\
\hline Water damaged building & 1 \\
\hline Working environment & 4 \\
\hline Art student & 1 \\
\hline Renovations to workplace & 1 \\
\hline Highly fragranced work environment & 1 \\
\hline Scientist & 1 \\
\hline Chemical factory & 1 \\
\hline Printing ink & I \\
\hline Postsurgery & 3 \\
\hline Bilateral breast implant rupture & 1 \\
\hline Medication & 3 \\
\hline Antibiotics (prednisone and Levaquin) & 2 \\
\hline Albendazole & I \\
\hline War & 2 \\
\hline Chemotherapy & 2 \\
\hline Ofloxacin & 1 \\
\hline Pesticides & 2 \\
\hline Chlordane & 1 \\
\hline Radiation & 1 \\
\hline EMR exposure & 1 \\
\hline Aspartame poisoning & 1 \\
\hline Cigarette smoke & 1 \\
\hline Contaminated water & 1 \\
\hline Defective product & 1 \\
\hline Mercury poisoning & I \\
\hline Carbon dioxide exposure & 1 \\
\hline Postmenopause & I \\
\hline No chemical insensitivity & 1 \\
\hline
\end{tabular}

Abbreviation: EMR, electromagnetic radiation.

health care (Table 5). Interestingly, over one-quarter of persons could not access medical care due to possible harm from electromagnetic exposure.

On a scale of $0-10$ with 10 being the most distress, the mean level of reported distress was 7.50 for unmet primary care needs. The highest mean levels of distress were reported for unmet psychological care needs (7.77) and "other" unmet medical needs (7.74). The mean level of distress from unmet gastroenterology needs was moderately high (7.20). 
Table 4 Health services utilized in the past year by 465 persons with environmental sensitivities

\begin{tabular}{ll}
\hline Type of health service & $\begin{array}{l}\text { Percent who accessed } \\
\text { health service }\end{array}$ \\
\hline Primary & 67.60 \\
Dental & 62.61 \\
Eye & 47.26 \\
Female care & 37.95 \\
Allergy/immunology & 39.90 \\
Mental health & 28.80 \\
Respiratory & 28.76 \\
Dermatology & 25.20 \\
Gastroenterology & 21.09 \\
Neurology & 19.23 \\
Male health & 4.91 \\
Other & 54.22 \\
\hline
\end{tabular}

Mean levels of distress among people who reported unmet dental, eye, reproductive, and dermatology care needs were similar: 6.30, 5.98, 6.20, and 5.78, respectively.

We constructed a correlation matrix with the major variables thought to relate to total unmet needs, including personal income, household income, age, level of disability, course of illness (improved versus worsened or fluctuating course), number of years ill, and level of education. All variables except age and education were significantly correlated with the total number of unmet health care needs. The variable that had the strongest correlation with the number of unmet health care needs was level of disability $(r=0.366$; $P<0.01$ ), with higher levels of disability associated with more unmet needs. Both personal and household incomes were significantly negatively correlated with total unmet needs ( $r=-0.289$ and $r=-0.231$, respectively; both $P<0.01$ ) with persons with lower incomes having more unmet needs. Years ill and course of illness (improved versus worsened or fluctuating) were significantly correlated with unmet needs as well ( $r=0.115$ and $r=-0.104$, respectively; both $P<0.05$ ) with longer illness and a worsening or fluctuating course of illness associated with more unmet needs (Table 6).

Participants were also asked if they had undergone surgery under general anesthesia during the past year. Of 465 participants, 179 reported having received general anesthesia for surgery. Of those who had received general anesthesia, $51 \%$ had been anesthetized by intravenous anesthesia only, $28 \%$ had received both intravenous and inhalant anesthesia, 6.0\% had received inhalant only, and $19 \%$ did not know which type had been used. Of those who had received general anesthesia, 54\% reported having experienced negative side effects. Participants who reported having experienced negative side effects from anesthesia use were then asked to list the side effects they had experienced.

The duration of reactions to anesthesia varied from $<1$ hour to $>7$ days. Of those who reported negative side effects, 36 participants (37.11\%) experienced these effects for more than 7 days, 17 (17.53\%) experienced them for $2-7$ days, and only five $(5.15 \%)$ reported side effects lasting for $<1$ hour (Table 7 ).

The most frequently reported side effects from anesthesia were nausea and vomiting, fatigue, reduced cognitive ability or having a "brain fog," and headaches. Several participants reported that their sensitivities either developed or worsened as a result of anesthesia use. Severe reactions such as difficulty breathing, depression, heart problems or palpitations, or body convulsions were also reported (Table 8).

\section{Discussion}

McColl et al ${ }^{9}$ pointed out that access to medical care for persons with disabilities involves much more than wait times and resource shortages; access also includes being able to navigate the physical environment, the level of expertise and attitudes of the providers, as well as funding and programming issues.

Table 5 Reasons for unmet needs by type of health care in 465 persons with environmental sensitivities

\begin{tabular}{|c|c|c|c|c|c|c|c|}
\hline \multirow[t]{2}{*}{ Reasons for unmet need } & \multicolumn{7}{|c|}{ Type of health care } \\
\hline & $\begin{array}{l}\text { Medical } \\
n=28 I\end{array}$ & $\begin{array}{l}\text { Dental } \\
\mathrm{n}=\mathbf{2 0 3}\end{array}$ & $\begin{array}{l}\text { Eye } \\
n=133\end{array}$ & $\begin{array}{l}\text { Male/female } \\
n=106\end{array}$ & $\begin{array}{l}\text { Dermatology } \\
n=100\end{array}$ & $\begin{array}{l}\text { GI } \\
n=104\end{array}$ & $\begin{array}{l}\text { Mental } \\
n=116\end{array}$ \\
\hline No MCS provider & $85.07 \%$ & $75.53 \%$ & $74.78 \%$ & $86.41 \%$ & $87.10 \%$ & $93.07 \%$ & $87.39 \%$ \\
\hline Possible harm from chemical exposure & $73.20 \%$ & $74.61 \%$ & $49.56 \%$ & $65.31 \%$ & $58.14 \%$ & $77.55 \%$ & $55.10 \%$ \\
\hline Could not afford & $61.96 \%$ & $70.68 \%$ & $69.23 \%$ & $43.62 \%$ & $47.78 \%$ & $45.35 \%$ & $61.68 \%$ \\
\hline No accessible office & $54.55 \%$ & $44.38 \%$ & $48.62 \%$ & $64.52 \%$ & $55.42 \%$ & $47.67 \%$ & $61.86 \%$ \\
\hline Did not feel well enough to go & $56.12 \%$ & $43.45 \%$ & $47.17 \%$ & $47.87 \%$ & $35.80 \%$ & $51.14 \%$ & $45.26 \%$ \\
\hline No available provider & $43.78 \%$ & $24.39 \%$ & $21.00 \%$ & $30.23 \%$ & $36.25 \%$ & $35.63 \%$ & $46.39 \%$ \\
\hline Possible harm from electromagnetic exposure & $26.87 \%$ & $23.31 \%$ & $14.00 \%$ & $21.84 \%$ & $14.10 \%$ & $28.24 \%$ & $16.67 \%$ \\
\hline No transportation & $24.45 \%$ & $18.01 \%$ & $20.79 \%$ & $21.84 \%$ & $15.19 \%$ & $17.50 \%$ & $21.51 \%$ \\
\hline Wait time too long & $22.22 \%$ & $1 \mathrm{I} .25 \%$ & II. I $\%$ & $16.85 \%$ & $21.52 \%$ & $27.71 \%$ & $18.48 \%$ \\
\hline Other & $50.50 \%$ & $38.36 \%$ & $42.55 \%$ & $43.53 \%$ & $42.50 \%$ & $51.32 \%$ & $51.69 \%$ \\
\hline
\end{tabular}

Abbreviations: $n$, number; GI, gastrointestinal; MCS, multiple chemical sensitivity. 
Table 6 Correlations among major variables for 465 persons with environmental sensitivities

\begin{tabular}{|c|c|c|c|c|c|c|c|c|}
\hline & $\begin{array}{l}\text { Personal } \\
\text { income }\end{array}$ & $\begin{array}{l}\text { Household } \\
\text { income }\end{array}$ & Age & $\begin{array}{l}\text { Level of } \\
\text { disability }\end{array}$ & $\begin{array}{l}\text { Course of illness } \\
\text { (improved) }\end{array}$ & Years ill & Education & $\begin{array}{l}\text { Total unmet } \\
\text { needs }\end{array}$ \\
\hline \multicolumn{9}{|l|}{ Personal income } \\
\hline Pearson correlation & 1 & $0.675^{* *}$ & 0.072 & $-0.295^{* *}$ & 0.063 & -0.058 & $0.198 * *$ & $-0.289 * *$ \\
\hline Sig (two-tailed) & & 0.000 & 0.144 & 0.000 & 0.196 & 0.236 & 0.000 & 0.000 \\
\hline $\mathrm{N}$ & 423 & 412 & 418 & 413 & 417 & 416 & 418 & 407 \\
\hline \multicolumn{9}{|l|}{ Household income } \\
\hline Pearson correlation & $0.675^{* *}$ & 1 & -0.050 & $-0.230 * *$ & 0.020 & $-0.133^{* *}$ & $0.124 *$ & $-0.23 I^{* *}$ \\
\hline Sig (two-tailed) & 0.000 & & 0.312 & 0.000 & 0.684 & 0.007 & 0.011 & 0.000 \\
\hline $\mathrm{N}$ & 412 & 420 & 415 & 410 & 415 & 413 & 415 & 401 \\
\hline \multicolumn{9}{|l|}{ Age } \\
\hline Pearson correlation & 0.072 & -0.050 & 1 & -0.009 & 0.088 & $0.323 * *$ & $0.139 * *$ & -0.049 \\
\hline Sig (two-tailed) & 0.144 & 0.312 & & 0.857 & 0.063 & 0.000 & 0.003 & 0.314 \\
\hline $\mathrm{N}$ & 418 & 415 & 453 & 447 & 452 & 451 & 453 & 429 \\
\hline \multicolumn{9}{|l|}{ Level of disability } \\
\hline Pearson correlation & $-0.295 * *$ & $-0.230 * *$ & -0.009 & I & $-0.117^{*}$ & 0.060 & $-0.148 * *$ & $0.366 * *$ \\
\hline Sig (two-tailed) & 0.000 & 0.000 & 0.857 & & 0.013 & 0.204 & 0.002 & 0.000 \\
\hline $\mathrm{N}$ & 413 & 410 & 447 & 448 & 447 & 446 & 448 & 423 \\
\hline \multicolumn{9}{|c|}{ Course of illness (improved) } \\
\hline Pearson correlation & 0.063 & 0.020 & 0.088 & $-0.117^{*}$ & 1 & 0.055 & 0.091 & $-0.104 *$ \\
\hline Sig (two-tailed) & 0.196 & 0.684 & 0.063 & 0.013 & & 0.245 & 0.052 & 0.031 \\
\hline $\mathrm{N}$ & 417 & 415 & 452 & 447 & 453 & 451 & 453 & 428 \\
\hline \multicolumn{9}{|l|}{ Years ill } \\
\hline Pearson correlation & -0.058 & $-0.133 * *$ & $0.323^{* *}$ & 0.060 & 0.055 & I & 0.025 & $0.115^{*}$ \\
\hline Sig (two-tailed) & 0.236 & 0.007 & 0.000 & 0.204 & 0.245 & & 0.599 & 0.017 \\
\hline $\mathrm{N}$ & 416 & 413 & 451 & 446 & 451 & 452 & 452 & 427 \\
\hline \multicolumn{9}{|l|}{ Education } \\
\hline Pearson correlation & $0.198 * *$ & $0.124^{*}$ & $0.139 * *$ & $-0.148 * *$ & 0.091 & 0.025 & I & 0.025 \\
\hline Sig (two-tailed) & 000 & 0.011 & 0.000 & 0.0002 & 0.052 & 0.599 & & 0.606 \\
\hline$N$ & 418 & 415 & 453 & 448 & 453 & 452 & 454 & 429 \\
\hline \multicolumn{9}{|l|}{ Total unmet needs } \\
\hline Pearson correlation & $-0.289 * *$ & $-0.23 I^{* *}$ & -0.049 & $0.366 * *$ & $-0.104 *$ & $0.115^{*}$ & 0.025 & 1 \\
\hline Sig (two-tailed) & 0.000 & 0.000 & 0.314 & 0.000 & 0.031 & 0.017 & 0.606 & \\
\hline $\mathrm{N}$ & 407 & 401 & 429 & 423 & 428 & 427 & 429 & 436 \\
\hline
\end{tabular}

Notes: $* P<0.05 ; * * P<0.01$

Abbreviation: Sig, significance.

These authors reported that obstacles to health care for persons with disabilities range from simple delays that inconvenience the general population to complete inability to access health care. The authors also found that people with disabilities had more unemployment and describe them as "clearly economically disadvantaged". Poorer health and poverty were associated with unmet needs, and the authors stated, "One can only

Table 7 Duration of negative reactions due to general anesthesia (number $=97$ )

\begin{tabular}{ll}
\hline Duration & $\%$ \\
\hline$<1$ hour & $5.15 \%$ \\
$1-5$ hours & $11.34 \%$ \\
$5-10$ hours & $7.22 \%$ \\
$10-24$ hours & $14.43 \%$ \\
$24-48$ hours & $6.19 \%$ \\
$2-7$ days & $17.53 \%$ \\
$>7$ days & $37.11 \%$ \\
\hline
\end{tabular}

conclude that the system appears to be geared to best serve those who are the easiest to serve". 9

The ability to afford health care and access an available provider were two barriers to health care access commonly reported by participants in the current study. This is consistent with the results of previous studies, which have shown that accessibility issues are a common cause of unmet health care needs. ${ }^{2,9}$ The most commonly reported barrier to health care in people with ES has been the inability to find a provider who understands their condition. Acceptability, therefore, has been found to be a barrier both in the present study and in prior research. ${ }^{8}$ The finding that persons with CS report that many health care providers fail to recognize and treat CS properly ${ }^{23}$ underscores the need for medical training regarding CS.

Washington et $\mathrm{al}^{2}$ found that being of a younger age, not having insurance, being an ethnic or racial minority, or having been diagnosed with a mental health disorder, were 
Table 8 Negative side effects from anesthesia use

\begin{tabular}{ll}
\hline Side effects & Frequency* \\
\hline Nausea/vomiting & 18 \\
Fatigue & 17 \\
Reduced cognitive ability/brain fog & 16 \\
Headaches & 14 \\
"Out of it" longer than usual & 13 \\
Pain (from anesthesia use, not surgery) & $1 \mathrm{I}$ \\
Dizziness & 9 \\
Difficulty breathing & 8 \\
MCS worsened & 8 \\
Heart problems/palpitations & 6 \\
Depression & 6 \\
Difficulty being anesthetized & 5 \\
Body convulsions & 5 \\
Rash & 5 \\
Undefined chemical reactions & 3 \\
Difficulty sleeping & 3 \\
"Pins and needles" sensation & 3 \\
Allergic reaction & 20 \\
Other & 3
\end{tabular}

Note: *Frequency was used because these reported reactions were written in rather than answered on structured questions.

Abbreviation: MCS, multiple chemical sensitivity.

highly correlated with unmet health care needs. Contrary to the findings of the study by Washington et al, ${ }^{2}$ a majority of participants in our study were over the age of 42 years (74.0\%), they did have some form of health insurance (84.3\%), and they were primarily Caucasian (94.1\%). Our findings show that persons with ES did not appear to be uneducated youth who lacked insurance. Instead, we found that many were middleaged Caucasian women who reported several unmet health care needs associated with their disability. However, in the current study, lower income, a higher level of disability, a worsened or fluctuating course of illness, and a longer period of illness were associated with higher total number of types of unmet medical needs. The association of unmet medical needs with both lower income and poorer health is consistent with the literature on unmet health care needs. ${ }^{3,4}$

The lack of accessible medical care for this population can be addressed through two pathways. First, health care providers in training need to receive appropriate training regarding chemical and electrical sensitivities. Medical providers have traditionally ignored exposure to toxic substances and electromagnetic radiation as causal in illness, and they preferred to focus on genetic (and sometimes pathogenic and psychogenic) factors. ${ }^{28,29}$ Second, providers' offices need to be accessible to persons with these disabilities. In some instances, particularly for CS, simply removing air fresheners, using safer pest control, and limiting the use of personal fragrance on personnel can address the bulk of the problem. More detailed needs can be addressed on an individual basis. Individuals with EHS may be unable to be in proximity to fluorescent lighting, diagnostic machines, and some computers. Seeing these persons in a room with less technology, or meeting outdoors - or even in their homes - may be necessary accommodations for health care providers to make. Recently, the National Council on Independent Living (www.ncil.org) made available a number of resources to help providers make their facilities accessible to those with chemical and electrical sensitivities. Though targeted to centers for independent living, a number of these resources could be helpful to medical providers as well. Because bodily reactions to environmental incitants can be life threatening, it is both ironic and clearly unacceptable that some patients must risk their safety in order to receive medical care. In addition, large numbers of respondents reported not feeling well enough to even attempt to get care. Yet, those who reported being more disabled, having been ill longer, and those who had worsened or fluctuated reported having high numbers of unmet needs. It seems that some people pass a threshold beyond which they are unable to access and benefit from medical care; yet, very little has been done to address this.

The contested nature of ES clearly contributes to the difficulty in accessing health care for persons with sensitivities. Despite 20 years of research and the availability of clear incidence, ${ }^{12,14,16,28,29}$ case series, ${ }^{30-32}$ and descriptive ${ }^{33-35}$ medical studies, patients continue to report that health care providers are either unaware of or do not accept the nature of these conditions. Thus, contested illnesses such as chemical and electrical sensitivities remain illnesses that you have "to fight to get" ${ }^{36}$ Doiron $^{37}$ found that even social workers who regularly saw persons with CS were unaware of the nature of their clients' needs. Though a subspecialty of environmental medicine exists in the US, mainstream providers generally do not treat ES.

In addition, understanding and providing services for both chemical and electrical hypersensitivity demands that we rethink our uncritical acceptance of all technology as "good" and be open to critical analysis of the health effects of such technology.

An additional grave concern is the high incidence of reported negative reactions to anesthesia in this population. Given that emergencies and other instances where surgeries are necessary may be beyond the control of the patient, it is of the utmost importance that health care providers both screen patients for chemical intolerance and attempt to prevent dangerous side effects from the use of anesthesia. Given that one-third of individuals stated that their reactions lasted longer than 1 week and that a large number of these reactions were neurological, the potential for long-term iatrogenic effects from anesthesia use appears evident. 


\section{Disclosure}

The authors report no conflicts of interest in this work.

\section{References}

1. Allin S, Grignon M, Le Grand J. Subjective unmet need and utilization of health care services in Canada: what are the equity implications? Soc Sci Med. 2010;70:465-472.

2. Washington DL, Bean-Mayberry B, Riopelle D, Yano EM. Access to care for women veterans: delayed healthcare and unmet need. $J$ Gen Intern Med. 2011;26(Suppl 2):655-661.

3. Wiltshire JC, Person SD, Kiefe CI, Allison JJ. Disentangling the influence of socioeconomic status on differences between African American and white women in unmet medical needs. Am J Public Health. 2009;99(9):1659-1665.

4. Bryant T, Leaver C, Dunn J. Unmet healthcare need, gender, and health inequalities in Canada. Health Policy. 2009;91:24-32.

5. Marshall EG. Do young adults have unmet healthcare needs? J Adolesc Health. 2011;49:490-497.

6. Ugalde A, Aranda S, Krishnasamy M, Ball D, Schofield P. Unmet needs and distress in people with inoperable lung cancer at the commencement of treatment. Support Care Cancer. 2012;20(2):419-423.

7. Hwang SS, Chang VT, Cogswell J, et al. Study of unmet need in symptomatic veterans with advanced cancer: incidence, independent predictors and unmet needs outcome model. J Pain Symptom Manage. 2004;25(5):421-432.

8. Nelson $\mathrm{CH}$, Park J. The nature and correlates of unmet healthcare needs in Ontario, Canada. Soc Sci Med. 2006;62:2291-2300.

9. McColl MA, Jarzynowska A, Shortt SED. Unmet healthcare needs of people with disabilities: population level evidence. Disabil Soc. 2010;25(2):205-218.

10. Ashford NA, Miller CS. Chemical Exposures: Low Levels and High Stakes. 2nd ed. New York, NY: John Wiley and Sons, Inc.; 1998.

11. Gibson PR, Vogel VM. Sickness related dysfunction in persons with self-reported multiple chemical sensitivity at four levels of severity. J Clin Nurs. 2009;18:72-81.

12. Caress SM, Steinemann AC. A review of a two-phase population study of multiple chemical sensitivities. Environ Health Perspect. 2003;111: 1490-1497.

13. Andersson L, Johansson A, Millqvist E, Nordin S, Bende M. Prevalence and risk factors for chemical sensitivity and sensory hyperreactivity in teenagers. Int J Hyg Environ Health. 2008;211(5-6):690-697.

14. Johansson A, Brämerson A, Millqvist E, Nordin S, Bende M. Prevalence and risk factors for self-reported odour intolerance: the Skövde population-based study. Int Arch Occup Environ Health. 2005; 78:559-564.

15. Berg ND, Linnegarg A, Dirksen A, Elberling J. Prevalence of selfreported symptoms and consequences related to inhalation of airborne chemicals in a Danish population. Int Arch Occup Environ Health. 2008; $81: 881-887$.

16. Hausteiner C, Bornschein S, Hansen J, Zilker T, Förstl H. Self-reported chemical sensitivity in Germany: A population-based survey. Int J Hyg Environ Health. 2005;208:271-278.

17. Hojo S, Ishikawa S, Kumano H, Miyata M, Sakabe K. Clinical characteristics of physician-diagnosed patients with multiple chemical sensitivity in Japan. Int J Hyg Environ Health. 2008;211(5-6):682-689.
18. Imai N, Imai Y, Kido Y. Psychosocial factors that aggravate the symptoms of sick house syndrome in Japan. Nurs Health Sci. 2008;10: 101-109.

19. Gibson PR, Lindberg A. Work accommodation for people with multiple chemical sensitivity. Disabil Soc. 2007;22(7):717-732.

20. Koch L, Rumrill P, Hennessey M, Vierstra C, Roessler RT. An ecological approach to facilitate successful employment outcomes among people with multiple chemical sensitivity. Work. 2007;29:341-349.

21. Gibson PR, Cheavens J, Warren ML. Social support in persons with self-reported sensitivity to chemicals. Res Nurs Health. 1998;21(2): $103-115$.

22. Gibson PR. Of the world but not in it: barriers to community access and education for persons with environmental sensitivities. Health Care Women Int. 2010;31(1):3-16.

23. Gibson PR, Elms AN, Ruding LA. Perceived treatment efficacy for conventional and alternative therapies reported by persons with multiple chemical sensitivity. Environ Health Perspect. 2003;111:1498-1504.

24. Engel LR, Gibson PR, Adler ME, Rice VM. Unmet medical needs in persons with self-reported multiple chemical sensitivity. Poster presented at: Annual Meeting of the Southeastern Psychological Association; March 20-23, 1996; Norfolk, VA

25. Johansson O. Electrohypersensitivity: State-of-the-art of a functional impairment. Electromagn Biol Med. 2006;25:245-258.

26. Sage C, Carpenter DO, editors. BioInitiative Report 2012. A Rationale for a Biologically-based Public Exposure Standard for Electromagnetic Fields (ELF and RF); 2012. BioInitiative Working Group; 2012. Available from: http://www.bioinitiative.org. Accessed January 1, 2014

27. Rizi HY, Dehghan H. Health problems from radiation of high-voltage facilities. Int J Env Health Eng. 2013;2(1):1.

28. Genius SJ. What's out there making us sick? J Environ Public Health. 2012;416-112.

29. Genius SJ, Lipp CT. Electromagnetic hypersensitivity: fact or fiction? Sci Total Environ. 2012;414:103-112.

30. Meggs WJ, Dunn KA. Bloch RM, Goodman PE, Davidoff AL. Prevalence and nature of allergy and chemical sensitivity in a general population. Arch Environ Health. 1996;51(4):275-282.

31. Kreutzer R, Neutra RR, Lashuay N. Prevalence of people reporting sensitivities to chemicals in a population-based survey. Am J Epidemiol. 1999;150(1):1-12.

32. Lax MB, Henneberger PK. Patients with multiple chemical sensitivities in an occupational health clinic: presentation and follow-up. Arch Environ Health. 1995;50:425-431.

33. Ishikawa S, Miyata M. Chemical sensitivity and its clinical characteristics in Japan. Asian Med J. 2000;43(1):7-15.

34. Miller CS. Chemical sensitivity: history and phenomenology. White paper. (Special Issue). Proceedings of the Conference on Low-Level Exposure to Chemicals and Neurobiologic Sensitivity. Toxicol Ind Health. 1994;10(4/5):253-276.

35. Saito M, Kumano H, Yoshiuchi K, et al. Symptom profile of multiple chemical sensitivity in actual life. Psychosom Med. 2005;67: 318-325.

36. Dumit J. Illnesses you have to fight to get: facts as forces in uncertain, emergent illnesses. Soc Sci Med. 2006:62:577-590.

37. Doiron N. People with Environmental Sensitivities: Life, Identity, and Services [doctoral thesis]. Toronto, ON: University of Toronto; 2007.
Journal of Multidisciplinary Healthcare

\section{Publish your work in this journal}

The Journal of Multidisciplinary Healthcare is an international, peerreviewed open-access journal that aims to represent and publish research in healthcare areas delivered by practitioners of different disciplines. This includes studies and reviews conducted by multidisciplinary teams as well as research which evaluates the results or conduct of such teams or

\section{Dovepress}

healthcare processes in general. The journal covers a wide range of areas and welcomes submissions from practitioners at all levels, from all over the world. The manuscript management system is completely online and includes a very quick and fair peer-review system. Visit http://www.dovepress.com/testimonials.php to read real quotes from published authors. 